\title{
Cause Traced to Component Failure
}

National Cancer Institute

\section{Source}

National Cancer Institute. Cause Traced to Component Failure. NCI Thesaurus. Code C139472.

Expected or random component failure without any design or manufacturing issue. 